\title{
Increment in molecular weight of poly (dimethylamino-ethylmethacrylate) based polymers cause strong red blood cell aggregation but not hemolytic response
}

\author{
B.I. Cerda-Cristerna ${ }^{1}$, H. Flores ${ }^{3}$, A. Pozos ${ }^{3}$, E. Perez ${ }^{2}$, Ch. Sevrin ${ }^{1}$, Ch. Grandfils ${ }^{1}$ \\ ${ }^{1}$ Interfacultary Center of Biomaterials, University of Liège, institut of Chemistry, Liège, 4000 Belgium \\ ${ }^{2}$ Institute of Physics, University of San Luis Potosí, San Luis Potosí, 78210, México \\ ${ }^{3}$ Faculty of Dentistry, University of San Luis Potosí, San Luis Potosí, 78210, México
}

\begin{abstract}
summary
Polycations are frequently reported to tailor drug delivery systems, there is still a need to better correlate their macromolecular features with their biocompatibility, in particular with blood. In this view, we have analysed the RBC aggregation and hemolysis response caused by poly (dimethylamino-ethylmethacrylate) or poly(ethyleneimine) under a free form, i.e. without their preliminary association with polyanionic drug. Our results highlight that the molecular weight of PDMAEMA significantly affects the RBC aggregation without inducing any hemolysis.
\end{abstract}

\section{Introduction}

Positively charged polymers, commonly named polycations, are widely used as carriers in drug delivery research. However, if cationic nanocarriers are intravenously injected, they may interact with several blood elements [1]. Their hemocompatibility have been reported by several authors, evaluating their ability to induce $\mathrm{RBC}$ aggregation and hemolysis. These tests have been particularly reported for two of the most common polycations explored for gene delivery: Poly(ethylenimine) (PEI) and poly(dimethylamino-ethylmethacrylate) (PDMAEMA). However, until now most of these tests have been usually applied considering polyelectrolyte complexes and not the free form of these polycations [2-3]. Considering that these complexes could potentially dissociate either in the blood itself or later on, it was also important to better analyze their biological behavior when diluted in the blood under a free form. Interaction between negatively charged red blood cells (RBC) and polycations is especially important because it may provoke RBC aggregation or hemolytic responses [2]. Although the decrease in Zeta potential resulting from the electrostatic adsorption of the polycations to the erythrocyte surface can explain such responses, other factors depending of the molecular weight and free polymer concentration could also affect this reactivity [4]. In this respect, RBC aggregation and hemolytic response were evaluated in human whole blood considering three PDMAEMA with Mw ranging from 10,000 to 40,000, one block copolymer of PDMAEMA-b-Poly(ethylene glycol) (PEG) copolymer (Mw 30,700) and a PEI (Mw : 10,000).

\section{Experimental methods}

Three linear PDMAEMA homopolymers of distinct Mw (Table 1) and one linear PDMAEMA-b-PEG copolymer were synthesized by living radical polymerization [2]. These polymers were extensively purified after preparation in view to eliminate any solvent, catalyst and monomer residues. Branched PEI was purchased from Polysciences Europe. Polymer solutions in isotonic PBS (pH 7.4) were diluted in whole blood (1/10 volume) in cylindrical Eppendorf tubes and incubated at $37^{\circ} \mathrm{C}$ during 15 to $240 \mathrm{~min}$ under roller agitation. After incubation, RBC aggregation was evaluated by inverted optical microscope $(25 \mathrm{x})$ analyzing at least 3 fields to have a statistic overview of the samples. Percentage of hemolysis was measured adopting ASTM method (F 756-00). Saponine $(0.8 \mathrm{mg} / \mathrm{mL})$ was adopted as positive control and PBS as negative control. 
Table 1 PDMAEMA based polymers and PEI from commercial origin.

\begin{tabular}{lccc}
\hline Polymer & Code & $\mathrm{Mn}, \mathrm{Mw}$ & Polymer concentration $(\mu \mathrm{g} / \mathrm{mL})$ \\
\hline PDMAEMA & P1 & 10,000 & $10,100,200,500,1000$ \\
PDMAEMA & P2 & 26,400 & \\
PDMAEMA & P3 & 40,000 & \\
PDMAEMA-b-PEG $\left(\mathrm{F}_{\text {DMAEMA }}=95 \%\right)$ & P4 & 30,700 & \\
PEI & P5 & 10,000 & \\
\hline
\end{tabular}

Table 2 Score of red blood cell aggregation: (-) single cells; $(+R)$ single cells, doublets, triplets and rouleaux; $(++)$ slight aggregation with presence of single cells; $(+++)$ strong aggregation with presence of single cells; $(++++)$ strong aggregation without presence of single cells; $(+++++)$ strong aggregation in all the visual fields.

\begin{tabular}{|c|c|c|c|c|c|c|c|c|c|c|c|c|c|c|c|c|c|c|c|c|}
\hline & \multirow{2}{*}{\multicolumn{5}{|c|}{$\frac{15 \text { minutes incubation }}{\text { Concentration }(\mu \mathrm{g} / \mathrm{ml})}$}} & \multicolumn{5}{|c|}{60 minutes incubation } & \multicolumn{5}{|c|}{120 minutes incubation } & \multicolumn{5}{|c|}{240 minutes incubation } \\
\hline & & & & & & \multicolumn{5}{|c|}{ Concentration $(\mu \mathrm{g} / \mathrm{ml})$} & \multicolumn{5}{|c|}{ Concentration $(\mu \mathrm{g} / \mathrm{ml})$} & \multicolumn{5}{|c|}{ Concentration $(\mu \mathrm{g} / \mathrm{ml})$} \\
\hline & 10 & 100 & 200 & 500 & 1000 & 10 & 100 & 200 & 500 & 1000 & 10 & 100 & 200 & 500 & 1000 & 10 & 100 & 200 & 500 & 1000 \\
\hline P1 & - & - & - & - & - & - & - & - & - & - & - & - & - & - & - & - & - & - & - & - \\
\hline $\mathrm{P} 2$ & - & - & - & ++ & +++ & - & - & - & ++ & ++++ & - & - & - & ++ & ++++ & - & - & - & ++++ & ++++ \\
\hline P3 & - & - & $+\mathrm{R}$ & +++ & ++++ & - & - & $+\mathrm{R}$ & +++ & ++++ & - & - & $+\mathrm{R}$ & +++ & ++++ & - & - & +++ & ++++ & +++++ \\
\hline P4 & - & - & - & - & - & - & - & - & - & - & - & - & - & - & - & - & - & - & - & - \\
\hline
\end{tabular}

\section{Results and discussion}

Results of aggregation are shown as score in Table 2. This shows that the Mw of the PDMAEMA largely affects the aggregation. Indeed the lowest $\mathrm{Mw}$ of this polycation (P1) does not induce any cell aggregation, whilst RBC aggregates are readily observed with $\mathrm{P} 2$ at $500 \mu \mathrm{g} / \mathrm{mL}$ and P3 at $200 \mu \mathrm{g} / \mathrm{mL}$ These observations support the assumption that the aggregation of the blood cells requires at least the combination of two physical factors. The first one relies upon a decrease of their Zeta potential by neutralisation of the negative charges present at the plasma membrane surface. The second one depends on a physical cross-linking between cells (bridging of cells with the poly electrolytes) which will be obviously facilitated by the use of longer polycation chains.

Fig. 1. Hemoglobin release is expressed in percentage. Responses lower than $2 \%$ are considered non-hemolytic; between 2 and 4\% slightly hemolytic; and higher than 4\% is considered hemolytic.

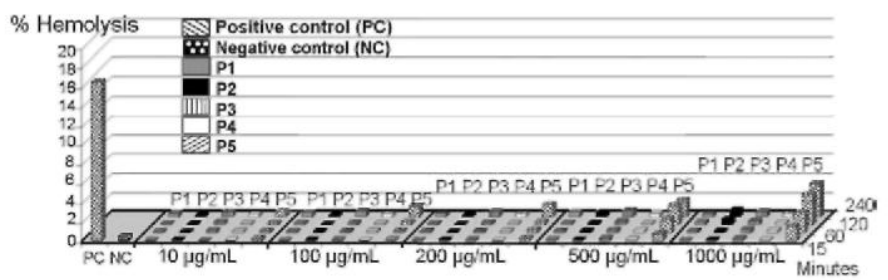

The difference of hemoreactivity of P4 is interesting to emphasis. Indeed in spite of its higher molecular weight, no aggregation has been noticed whatever the duration and polycation concentration assessed. This profound difference in hemoreactivity can be explained by the steric protection afforded by the PEG moieties present in this copolymer.

Indeed it can be anticipated that the shielding of the PEG chains could significantly reduce the cross-linking action of the polycation segments. A slight RBC aggregation was observed with PEI, but only at the highest concentration $(1 \mathrm{mg} / \mathrm{mL})$ and after $4 \mathrm{~h}$ of incubation. Compared to PDMAEMA this difference could be at least explained by the difference in macromolecule flexibility between these two polymers. In this respect the hemolytic ability is most interesting to compare between PEI and the PDMAEMA based polymers. PEI 
provokes indeed higher hemoglobin release by analogy to the other polycations evaluated. Indeed whatever their molecular weight and composition no hemolytic response has been noticed with the PDMAEMA's under our experimental conditions (image 2). In opposite, PEI caused slight hemolytic response depending on incubation time and concentration. In distinct mammalian cells, the toxicity of PEI is related to bind of this polycation to plasma membrane proteoglycans, causing membrane destabilization with redistribution of phosphatidylserine [5]. Cytotoxicity has been observed in mammalian cells incubated with PDMAEMA. It has been related to internalization of polymer [6]. In RBC, toxic mechanism could be similar to mechanism observed for mammalian cells. Based in our results, the cytotoxicity activity for RBC is stronger for the PEI than PDMAEMA.

\section{Conclusion}

The present experiment showed that the RBC aggregation can proceed very quickly and intensively when incubated with homoPDMAEMA of Mw above than 10,000. This aggregation ability can however be totally prevented if PEG moieties are grafted in the polycation sequence. The comparison in the hemoreactivity of the PEI with homoPDMAEMA was interesting highlighting clearly that: RBC aggregation and hemolysis are independent responses, and the difference in membrane interaction between two families of polycations.

\section{Acknowledgement}

Financial support from the EU FP6 IP NanoBioPharmaceutics, is gratefully acknowledged.

\section{References}

[1] B. Rihova, Biocompatibility of biomaterials: hemocompatibility, immunocompatibility and biocompatibility of solid polymeric materials and soluble targetable polymeric carriers, Adv. Drug Del. Rev. 21 (1996) 157-176.

[2] S. Pirotton, C. Muller, N. Pantousier, F. Botteman, S. Collinet, Ch. Grandfils, G. Dandrifosse, P. Degée, P. Dubois, M. Raes, Enhancement of transfection efficiency through rapid and noncovalent post-PEGylation of poly(dimethylaminoethyl methacrylate)/DNA complexes, Pharm. Res. 21 (2004) 1471-1479.

[3] P. Dubruel, B. Christiaens, B. Vanloo, K. Bracke, M. Rosseneu, J. Vandekerckhove, E. Schacht, Physicochemical and biological evaluation of cationic polymethacrylates as vectors for gene delivery, Eur. J. Pharm. Sci. 18 (2003) 211-220.

[4] E. Moreau, M. Domurado, P. Chapon, M. Vert, D.J. Domurado, Biocompatibility of polycations: in vitro agglutination and lysis of red blood cells and in vivo toxicity, Drug Target. 10 (2002) 161-173.

[5] A. Rachel, R.A. Jones, H. Maree, M.H. Poniris, R. Mark, M.R. Wilson, pDMAEMA is internalised by endocytosis but does not physically disrupt endosomes, J. Control. Release. 18 (2004) 379-391.

[6] S.M. Moghimi, P. Symonds, C. Murray, ACh. Hunter, G. Debska, A. Szeczyk, A two stage poly (ethylenimine)-mediated cytotoxicity: implications for gene transfer/ therapy, Mol. Ther. 11 (2005) 990-995. 